Check for updates

Cite this: Mater. Chem. Front., 2019, 3, 1532

Received 15th April 2019,

Accepted 14th May 2019

DOI: 10.1039/c9qm00243j

rsc.li/frontiers-materials

\section{Construction of two-dimensional supramolecular nanostructure with aggregation-induced emission effect via host-guest interactions $\dagger$}

\author{
Hui Liu, ${ }^{a}$ Qingyan Pan, ${ }^{a}$ Chenyu Wu, (D) a Jing Sun, (D) ${ }^{a}$ Tao Zhuang, ${ }^{a}$ \\ Tongling Liang, (D) ${ }^{\mathrm{b}}$ Xueluer $\mathrm{Mu}^{a}{ }^{a}$ Xianfeng Zhou, ${ }^{a}$ Zhibo Li (D) ${ }^{a}$ and \\ Yingjie Zhao (D) *a
}

\begin{abstract}
A tetraphenylethene (TPE) based water-soluble molecule was synthesized. The two-dimensional supramolecular nanostructure with an evident aggregation-induced emission effect was constructed through the host-guest interactions between the TPE derivative and CB[8]. The assembly process and the 2D structure were confirmed by ${ }^{1} \mathrm{H}-\mathrm{NMR}$ spectroscopy, SEM, TEM and SAXS. A high affinity for DNA and significant fluorescence enhancement were observed for the TPE derivative, making it an excellent biological fluorophore stain for the intracellular DNA imaging of live cells.
\end{abstract}

\section{Introduction}

Tetraphenylethene (TPE), a well-known molecule with the classical aggregation-induced emission (AIE) effect has been demonstrated to be an excellent moiety for constructing the functional materials. ${ }^{1-7}$ The AIE materials have been widely used to construct chemosensors, bio-probes, optical devices and so on because of their excellent luminescent properties and unique superiority compared to the materials with conventional aggregationcaused quenching (ACQ) effect. ${ }^{8-17}$ The mechanism of the AIE effect is generally accepted as the restriction of intramolecular motions (RIM) of luminescent unit when they exist in poor solvents or solid state. ${ }^{18}$ In general, the restriction is caused by the self-aggregation of the AIE molecules. Recently, non-covalent host-guest recognition has been demonstrated to be an efficient way to restrict the intramolecular motions of the AIE molecules. ${ }^{19-21}$ This offers an opportunity for the preparation of new AIE materials. In addition, this strategy avoids the variations in the energy levels and molecular structures, as the whole process is a physical change. Several fluorescent host-guest complexes have been constructed based on the TPE building blocks. ${ }^{19-21}$ However, the reported supramolecular polymers or complexes with AIE properties in the aqueous phase are still relatively less, especially the two-dimensional (2D) supramolecular structures..$^{22-25}$ This limits the application of these smart supramolecular sensors in the biological systems. It is

${ }^{a}$ College of Polymer Science and Engineering, Qingdao University of Science and Technology, Qingdao 266042, P. R. China. E-mail: yz@qust.edu.cn

${ }^{b}$ Institute of Chemistry, Chinese Academy of Sciences, Beijing 100190, P. R. China $\dagger$ Electronic supplementary information (ESI) available: Synthesis procedures, ${ }^{1} \mathrm{H}$-NMR spectra, ${ }^{13} \mathrm{C}$ NMR, MS, absorption spectrum, fluorescence spectra. See DOI: $10.1039 / \mathrm{c} 9 \mathrm{qm} 00243 \mathrm{j}$ known that 2D structures and materials have received tremendous attention and presented a series of special advantages over the conventional polymeric materials due to their unique structures in a 2D plane. ${ }^{26-29}$ However, it is still challenging to fabricate such materials that are self-assembled only in a 2D plane. Disordered or cross-linked structures are normally obtained through traditional synthetic strategy. The dynamic host-guest interactions offer an ideal approach to construct highly ordered 2D structures due to their self-healing properties. For example, the 2D supramolecular organic framework (SOF) has been widely accepted for its good orderliness and solubility. ${ }^{30-36}$

In this work, a fabricated 2D supramolecular nanostructure with outstanding AIE properties was prepared in aqueous phase (Scheme 1). A TPE derivative with four 4-vinylpyridium arms as the guest molecule was designed (Scheme 1a). $\mathrm{CB}[8]$ played the role of the host macrocycle. Through a head-to-tail self-assembling process, a liner supramolecular assembly intermediate formed first followed by a well ordered fluorescent layered 2D aggregate (Scheme $1 \mathrm{~b}$ ). The self-assembling process and the structure were confirmed by ${ }^{1} \mathrm{H}-\mathrm{NMR}$ spectroscopy, DLS, TEM, AFM and SAXS experiments. An evident AIE effect was achieved by restricting the intramolecular rotation of the aromatic rings. Except $\mathrm{CB}[8]$, a high affinity for DNA was also observed accompanied by the significant fluorescence enhancement for the guest molecule. This water-soluble TPE derivative was successfully applied for the visualisation of DNA in cells with excellent contrast.

\section{Results and discussion}

The synthesis of the guest molecule 1 was straightforward (Fig. S1, ESI $\dagger$ ). Four vinylpyridine units were attached onto 
a)

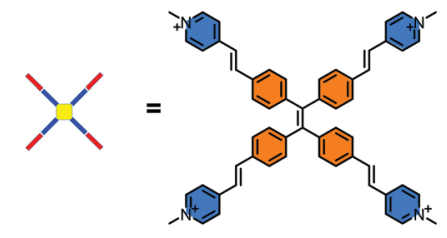

1

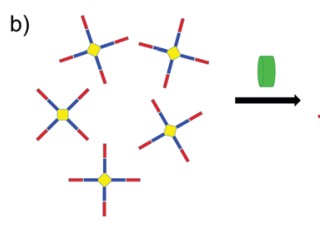

Weak-fluorescent

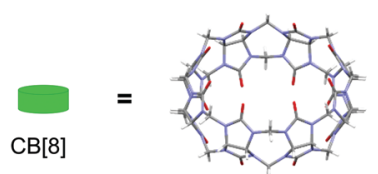

$\mathrm{CB}[8]$

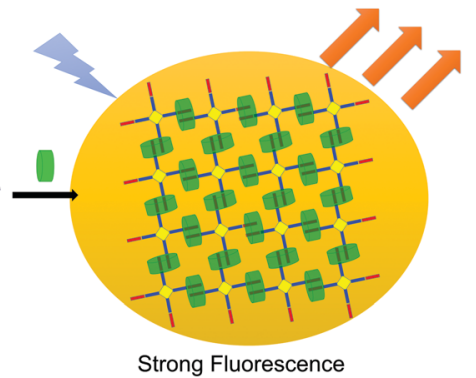

Scheme 1 (a) Chemical structure of the guest molecule 1 and host CB[8]; (b) schematic representation of the formation of 2D supramolecular structure in a head-to-tail self-assembled mode and stepwise fluorescence enhancement.

the periphery of the tetraphenyl ethylene core by Heck reaction to form compound 2 as the intermediate. Hydrophobic compound 2 was converted to hydrophilic compound $\mathbf{1}$ by further methylation. For detailed synthesis procedures, see the synthesis section in the supporting information. Compound 2 is a highly fluorescent compound both in the solid state and solution. On the other hand, the methylation makes compound 1 almost nonfluorescent both in the solution and solid state. Compound 1 itself shows evident aggregation behavior in $\mathrm{H}_{2} \mathrm{O}$, as demonstrated by ${ }^{1} \mathrm{H}-\mathrm{NMR}$ spectroscopy and DLS experiments. Fig. S2 (ESI $\dagger$ ) shows the ${ }^{1} \mathrm{H}$-NMR spectra of $\mathbf{1}$ in $\mathrm{D}_{2} \mathrm{O}$ at concentrations of $0.09,0.19,0.37,0.75$ and $1.5 \mathrm{mM}$ at room temperature. At a lower concentration, clear peaks were observed and could be easily assigned. With the increase in the concentration, several new sets of peaks appeared due to the aggregation. For example, at $1.5 \mathrm{mM}, 8$ sets of peaks were observed that could be demonstrated by the splits of $\mathrm{CH}_{3}$ peak located at around $4.2 \mathrm{ppm}$. The DLS experiment also demonstrated that the aggregation was a concentration dependent process (Fig. S3, ESI $\dagger$ ). Then, the high temperature ${ }^{1} \mathrm{H}$-NMR was performed. At the concentration of $0.75 \mathrm{mM}$ in $\mathrm{D}_{2} \mathrm{O}$, the peaks became clear with the increase in the temperature. At $60{ }^{\circ} \mathrm{C}$, only one clear set of peaks was observed (Fig. S4, ESI $\dagger$ ). However, at the concentration of $1.5 \mathrm{mM}$ in $\mathrm{D}_{2} \mathrm{O}$, even when the temperature was increased to $90{ }^{\circ} \mathrm{C}$, no evident improvement was observed in the ${ }^{1} \mathrm{H}$-NMR spectrum (Fig. S5, ESI $\dagger$ ). This result indicated that compound 1 showed aggregation behaviour in $\mathrm{H}_{2} \mathrm{O}$ and it was a concentration dependent process. High temperature could inhibit the aggregation process to a certain extent. However, as a classical AIE molecule, compound 1 itself showed no appreciable AIE fluorescence in $\mathrm{H}_{2} \mathrm{O}$, and this result indicated that the self-aggregation process was not strong enough to restrict the intramolecular rotation of the building blocks.

The self-assembly of $\mathbf{1}$ in the presence of $\mathrm{CB}[8]$ was then studied (Fig. 1a). The concentration of 1 was chosen as $0.37 \mathrm{mM}$ to avoid the influence of the self-aggregation and satisfy the measurement of ${ }^{1} \mathrm{H}$ NMR. ${ }^{1} \mathrm{H}-\mathrm{NMR}$ titration spectra showed that with the increase of $\mathrm{CB}[8]$, the original ${ }^{1} \mathrm{H}$-NMR signals
$\left(\mathrm{H}_{\mathrm{A}}-\mathrm{H}_{\mathrm{F}}\right)$ disappeared gradually accompanied by an emergence of two new sets of peaks. When the ratio of compound $\mathbf{1}$ and $\mathrm{CB}[8]$ reached to $1: 1$, the original peaks completely disappeared. Two new sets of peaks were observed clearly $\left(\mathrm{H}_{\mathrm{a}}-\mathrm{H}_{\mathrm{f}}, \mathrm{H}_{\mathrm{a}^{\prime}}-\mathrm{H}_{\mathrm{f}^{\prime}}\right)$. Continuous addition of 2.0 equiv. of $\mathrm{CB}[8]$ caused the signals of $\mathrm{H}_{\mathrm{a}}-\mathrm{H}_{\mathrm{f}}$ and $\mathrm{H}_{\mathrm{a}^{\prime}}-\mathrm{H}_{\mathrm{f}^{\prime}}$ to disappear completely (Fig. 1a). 2D COSY ${ }^{1} \mathrm{H}$ NMR spectra confirmed the affiliation of the protons, which were from two sets of peaks in the 1:1 complex (Fig. S6a, ESI $\dagger$ ). One set of peaks showed slight downfield shifts, while the other showed significant upfield shifts (Fig. 1a). The upfield shifts of protons was attributed to the shielding effect of the $\mathrm{CB}[8]$. The integral area of these two sets of peaks were identical. This result indicated that an intermediate with two different environments of the "arms" 4-vinylpyridium building blocks in the presence of 1.0 equiv. of $\mathrm{CB}[8]$ formed in the solution. One of the "arms" was located in the cavity of $\mathrm{CB}[8]$, while the other one was not (Fig. 1a). 2D NOE ${ }^{1} \mathrm{H}$ NMR data confirmed the intermolecular NOE connections between $\mathrm{H}_{\mathrm{a}}$ and $\mathrm{H}_{\mathrm{b}}, \mathrm{H}_{\mathrm{a}^{\prime}}$ and $\mathrm{H}_{\mathrm{b}^{\prime}}, \mathrm{H}_{\mathrm{d}}$ and $\mathrm{H}_{\mathrm{e}}$, $\mathrm{H}_{\mathrm{d}^{\prime}}$ and $\mathrm{H}_{\mathrm{e}^{\prime}}, \mathrm{H}_{\mathrm{b}^{\prime}}$ and $\mathrm{H}_{\mathrm{c}^{\prime}}$ of $\mathbf{1}$ (Fig. S6b, ESI $\dagger$ ). However, it was still difficult to judge the self-assembled mode of the compound. Since the head-to-tail self-assembly would lead to the formation of the supramolecular polymer, the head-to-head self-assembly would lead to the formation of dimers.

To further confirm the structure of the intermediate, DLS measurement was performed. The hydrodynamic diameter $\left(D_{\mathrm{h}}\right)$ of the self-assembled structures of the guest molecule and $\mathrm{CB}[8]$ solution in water was much larger than that of $\mathbf{1}$ alone in water at the concentration of $0.1 \mathrm{mM}$ (Fig. S7, ESI $\dagger$ ). SEM and TEM results indicated a nanoribbon morphology (Fig. S8, ESI $\dagger$ ). The supramolecular complex $(1: 1)$ was rather stable even at $90{ }^{\circ} \mathrm{C}$ according to the high temperature ${ }^{1} \mathrm{H}-\mathrm{NMR}$ (Fig. S9, ESI $\dagger$ ). All the above results indicated the formation of a supramolecular polymer intermediate.

When 2.0 equiv. of $\mathrm{CB}[8]$ was introduced into the solution, precipitation occurred immediately. This event indicated that further self-assembly in the presence of more $\mathrm{CB}[8]$ led to larger aggregates, which precipitated from the solution. The precipitates 


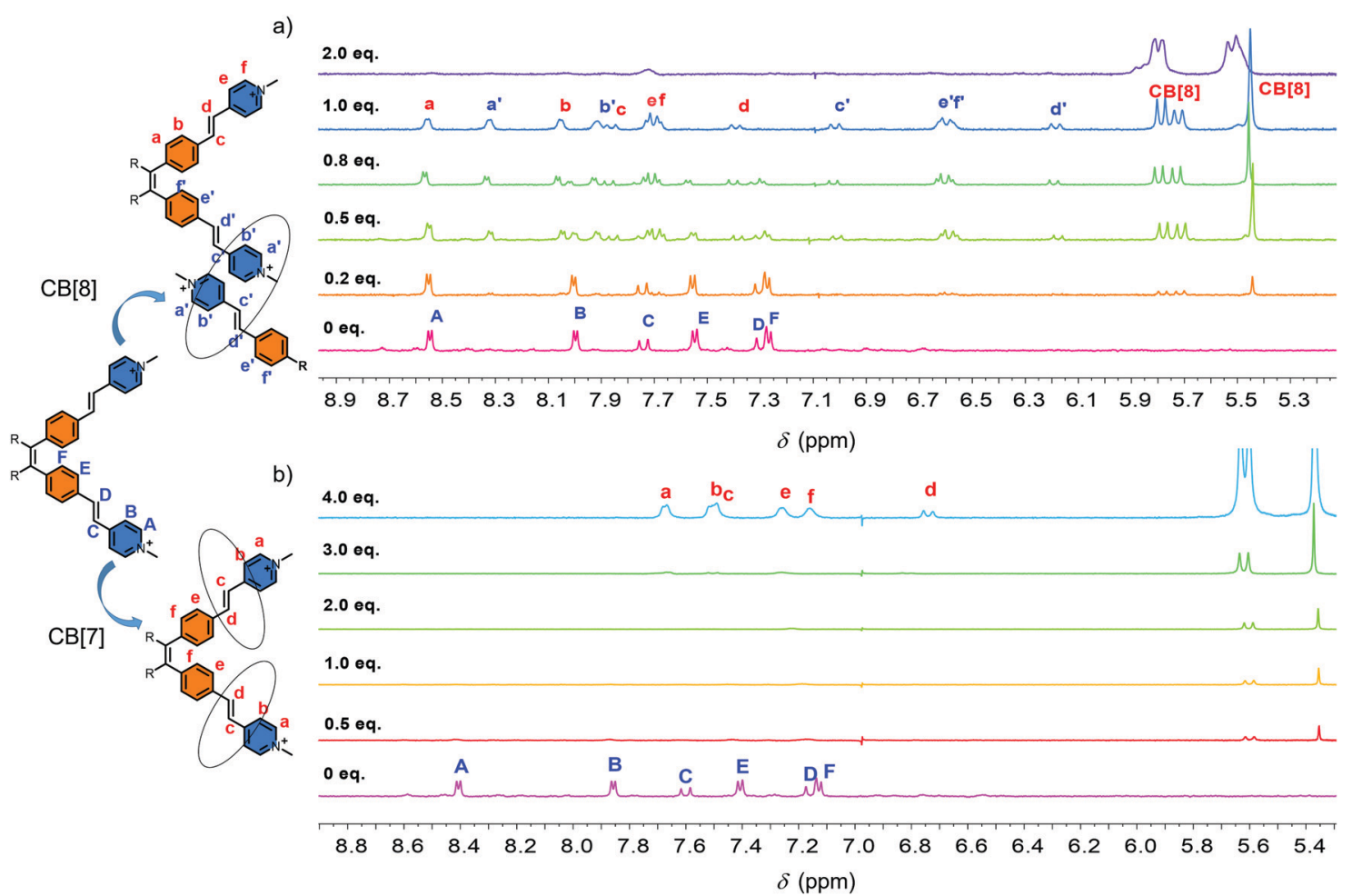

Fig. $1{ }^{1} \mathrm{H}$-NMR spectra: (a) $1(0.37 \mathrm{mM})$ in $\mathrm{D}_{2} \mathrm{O}$ in the presence of $0,0.2,0.5,0.8,1.0,2.0$ equiv. of $\mathrm{CB}[8]$ at $25^{\circ} \mathrm{C}$; (b) $1(0.37 \mathrm{mM})$ in $\mathrm{D}_{2} \mathrm{O}$ in the presence of $0,0.5,1.0,2.0,3.0,4.0$ equiv. of $\mathrm{CB}[7]$ at $25^{\circ} \mathrm{C}$.

showed high fluorescence (Fig. S10, ESI $\dagger$ ). The morphology of the as-formed self-assembled structures of 1_CB[8] complex was then characterized. Optical microscopy (OM), AFM, SEM and TEM results revealed the formation of regular square structures (Fig. 2). The average side length was $2-3 \mu \mathrm{m}$. The AFM data showed that the surface was flat and the thicknesses of these squares were in the range of 50 to $100 \mathrm{~nm}$. Most importantly, a layer by layer structure was observed by the cross-section analysis (Fig. 2e and f). The thickness of each layer was around $1.8 \mathrm{~nm}$, and it was consistent with the outer diameter of $\mathrm{CB}[8]$ of $1.75 \mathrm{~nm}$ (Fig. 2f). These results together with the ${ }^{1} \mathrm{H}-\mathrm{NMR}$ spectra and DLS study mentioned above strongly suggested the formation of 2D supramolecular structures from the self-assembly of $\mathbf{1}$ and $\mathrm{CB}[8]$. With the aid of simulation studies, a stable 1_CB[8] (1:2) complex was found by the PM5 semi-empirical calculation, confirming that the $\mathrm{CB}[8]$ host could accommodate two guests
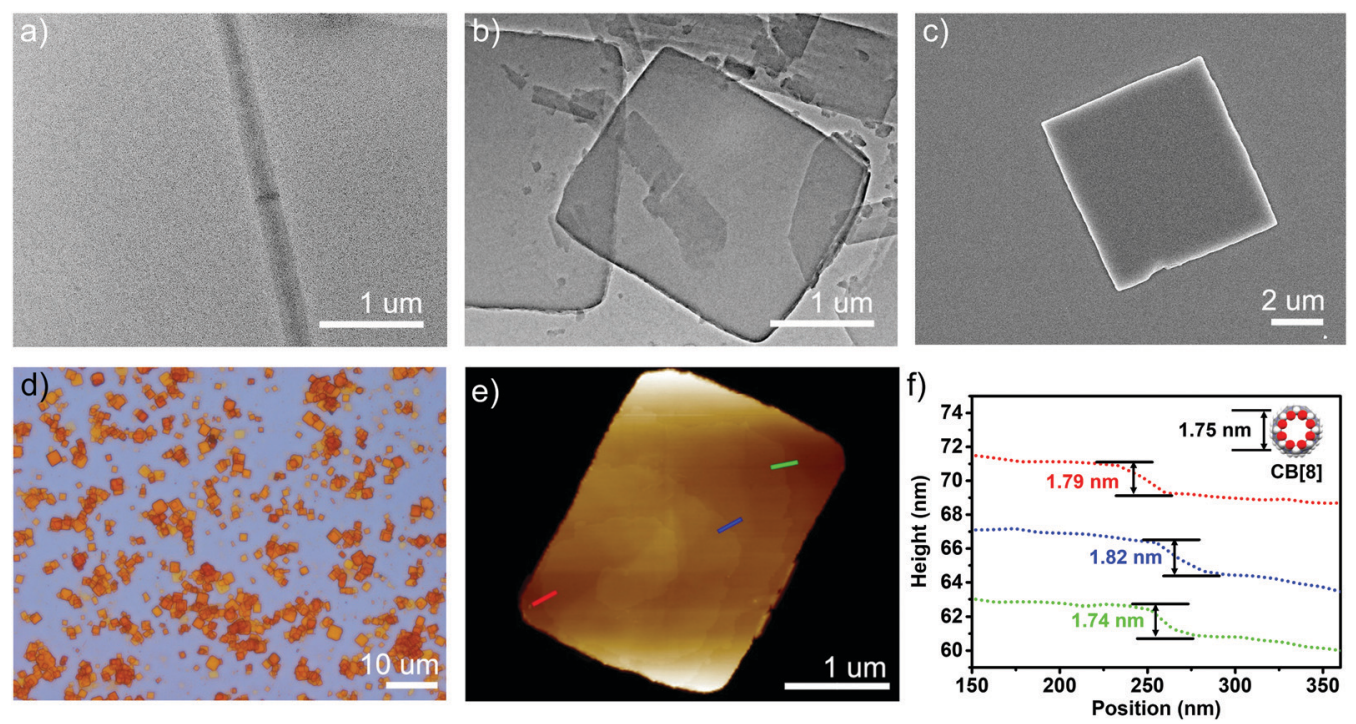

Fig. 2 (a) TEM images of 1 (0.37 mM); (b) TEM; (c) SEM; (d) optical microscope; (e) AFM images and (f) the height analysis of the self-assembled structures for 1_CB[8] (1:2). 
to form an ordered $2 \mathrm{D}$ structure, in which $\mathrm{CB}[8]$ could act as a linker of two guest molecules (Fig. S11, ESI $\dagger$ ). The pyridinium moieties of the "arms" were encapsulated in the cavity of $\mathrm{CB}[8]$ to achieve the host-guest system.

To characterize the supramolecular structure of the assembled sheets, we conducted small angle X-ray scattering (SAXS) analysis. As shown in Fig. 3a, the obtained SAXS profile exhibited a major pair of twin peaks at $1.89^{\circ}$ and $1.81^{\circ}$ as well as a smaller pair of twin peaks at $1.62^{\circ}$ and $1.57^{\circ}$. As these signals corresponded to the crystal planes with the highest atom densities, we simulated the supramolecular crystal structure based on molecular mechanics. An optimized periodic structure with an energy minimum was obtained as shown in Fig. 3b. Apparently, due to the rearrangement of $\mathrm{CB}[8]$ driven by the steric force minimization, the assembled structure carried a periodic asymmetry with a long axis and a short axis. As expected, the plane groups with the highest atom density (Fig. 3b, mostly contributed by TPE units, long axis denoted as green and short axis denoted as yellow) exhibited the plane spacing of $1.95 \mathrm{~nm}$ and $1.74 \mathrm{~nm}$, and the data was in excellent agreement with the major pair of twin peaks as shown in Fig. 3a $(1.89 \mathrm{~nm}$ and $1.81 \mathrm{~nm})$. We further noticed that the alignment of $\mathrm{CB}[8]$ also contributed to a set of plane groups with the second highest atom density (Fig. 3b, long axis denoted as blue and short axis denoted as red), which exhibited the plane spacing of $1.57 \mathrm{~nm}$ and $1.44 \mathrm{~nm}$, in excellent agreement with the second pair of twin peaks as

a)

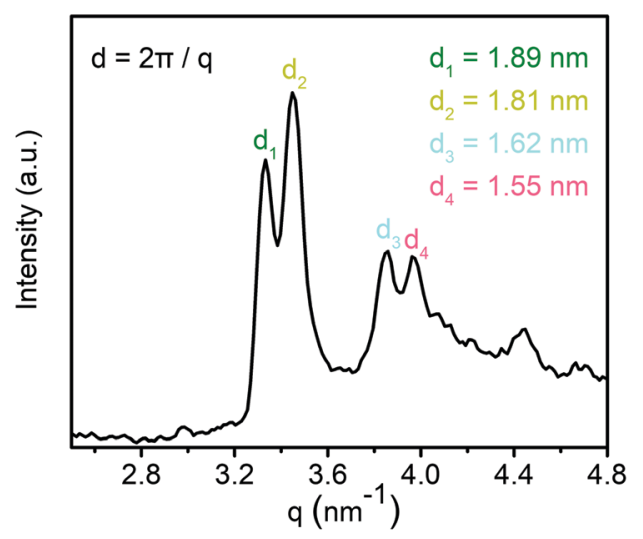

b)

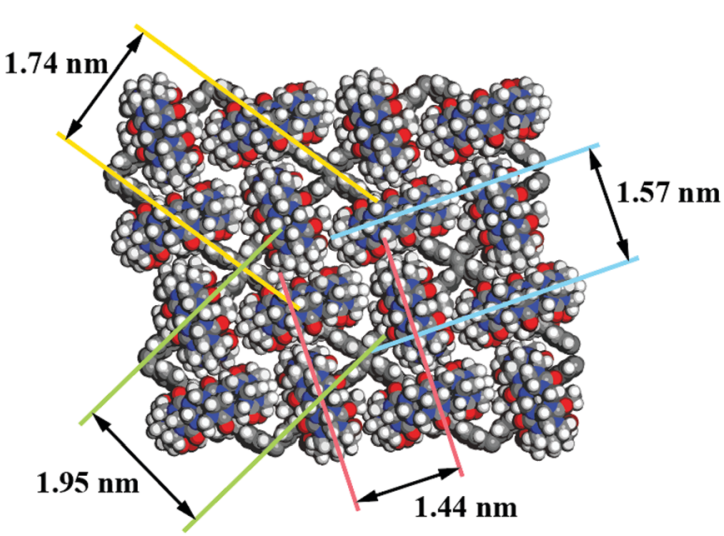

Fig. 3 (a) SAXS profile of the obtained 1_CB[8] complex; (b) optimized periodic structure with periodic asymmetry. seen in Fig. 3a (1.62 nm and $1.55 \mathrm{~nm})$. As such, the formation of topological 2D structure with a periodic asymmetrical character through supramolecular assembly was well confirmed by the combination of SAXS analysis and molecular mechanics simulation.

To better understand the self-assembly process, $\mathrm{CB}$ [7] with a smaller cavity was used as a reference host. The ${ }^{1} \mathrm{H}-\mathrm{NMR}$ titration data showed a completely different trend (Fig. 1b). The addition of $\mathrm{CB}[7]$ caused the disappearance of the ${ }^{1} \mathrm{H}-\mathrm{NMR}$ signal in the beginning. With the increase in $\mathrm{CB}[7]$, new peaks emerged gradually. When 4.0 equiv. of $\mathrm{CB}[7]$ was introduced, a new set of peak that showed significant downfield shifts was observed clearly (Fig. 1b). No precipitation and significant fluorescence enhancement were observed in the solution. To clarify the reason of the disappearance of the NMR signals, DLS measurement was performed. Fig. S12 (ESI $\dagger$ ) shows the $D_{\mathrm{h}}$ of the self-assembled structures of 1 and $\mathrm{CB}[7]$ at different ratios of $1: 0,1: 1,1: 4$ respectively. With the increase in $\mathrm{CB}[7]$, an increased tendency of $D_{\mathrm{h}}$ was observed first followed by an evident decrease in the end. This indicated that $\mathrm{CB}[7]$ might cause an aggregation at the beginning. Because some of the terminal hydrophilic groups were enclosed by $\mathrm{CB}[7]$, an amphiphilic structure was formed. The amphiphilic structure facilitated the aggregation process. However, when enough $\mathrm{CB}[7]$ were introduced, the full encapsulation of the terminal hydrophilic groups influenced the amphiphilic structure. As a result, the aggregation was suppressed. In the end, the $D_{\mathrm{h}}$ of $1-\mathrm{CB}[7]$ (1:4) was relatively small, and it was similar with that of $\mathbf{1}$ alone in water at the same concentration (Fig. S12, ESI $\dagger$ ). These results demonstrated the formation of supramolecular polymers between 1 and $\mathrm{CB}[8]$ and an individual supramolecular complex between 1 and $\mathrm{CB}[7]$ at a ratio of $1: 4$.

Since the TPE-based building block had been proved to be an excellent AIE molecule, it was interesting to investigate the photophysical properties of the guest molecules and the selfassembled structures. Solid state fluorescence signal enhancement was observed for 1_CB[8] complex. As shown in Fig. S10 (ESI $\dagger$ ), the fluorescence emission spectrum of $\mathbf{1}$ was almost non-fluorescent, while a strong emission peak at $609 \mathrm{~nm}$ was observed for the 1_CB[8] complex. 10-Fold increase in the fluorescence intensity was observed after the self-assembly of 1 with $\mathrm{CB}[8]$ compared with molecule 1 itself. The absolute quantum yield of the fluorescence $\left(\Phi_{\mathrm{FL}}\right)$ was evaluated to be $28 \%$ by using an integrating sphere method. This could be explained by AIE theory. Molecule 1 was weakly fluorescent due to the free rotation of the building blocks, and this led to the thermal relaxation of the excited $S_{1}$ state. In the presence of $\mathrm{CB}[8]$, the four 4-vinylpyridium "arms" were co-encapsulated in the cavity of $\mathrm{CB}[8]$ through a head-to-tail self-assembly mode, leading to the formation of a rigid $2 \mathrm{D}$ structure. Free rotation was inhibited due to the confined spaces and thus dictated energy relaxation of $S_{1}$ to $S_{0}$ through radiation.

In consideration of the potential AIE effect of the guest molecule 1 and high fluorescent property of 1_CB[8] complex, we further studied $\mathbf{1}$ and the as-formed 2D nanostructure as the fluorescent dye to stain the DNA. It has been reported that pyridinium is a good DNA binder and has been shown to interact with DNA double helices. ${ }^{23,37}$ The presence of cationic 
groups is known to display strong affinity for DNA through electrostatic interaction with the sugar phosphate backbone. The combination of 1 with $\lambda$ DNA was then studied. The fluorescence spectra of the titration experiment showed that the addition of $\lambda$ DNA induced marked enhancement (10-fold) of the fluorescence. In the absorption spectrum, evident hypochromism of the absorptions $(\sim 70 \%)$ and red shifts $(18 \mathrm{~nm})$ of the maxima (Fig. S13a, ESI $\dagger$ ) were observed. The dissociation constant of 1 and $\lambda$ DNA was measured to be $54.34 \mu \mathrm{M}$, which also indicated the high affinity of 1 to DNA (Fig. S14, ESI $\dagger$ ). For the 1_CB[8] complex, the UV-vis spectrum showed a similar property (Fig. S13b, ESI $\dagger$ ). However, the intensity of the fluorescence spectrum first decreased and red-shifted and then increased. This phenomenon may be caused due to the competition between the host $\mathrm{CB}[8], \lambda \mathrm{DNA}$ and the guest molecule 1. Both of the UV-vis and fluorescence titration spectra clearly indicated the strong binding of $\mathbf{1}$ to the DNA and resulted in fluorescence enhancement. To examine the performance of $\mathbf{1}$ for staining DNA in cells, HeLa cells were treated with aqueous solutions of $\mathbf{1}$. The cells were incubated with solution of $\mathbf{1}$ at room temperature for $30 \mathrm{~min}$ and were then washed to remove the excess of the unbound dye. The slides were mounted and imaged by fluorescence microscopy. Fig. $4 \mathrm{~d}$ showed that an intense emission from the dye was observed in the nucleus, and indicated that the guest molecule 1 could bind selectively to DNA. The control experiment with the classical Hoechst dye showed similar colored positions (Fig. 4c), further demonstrating compound
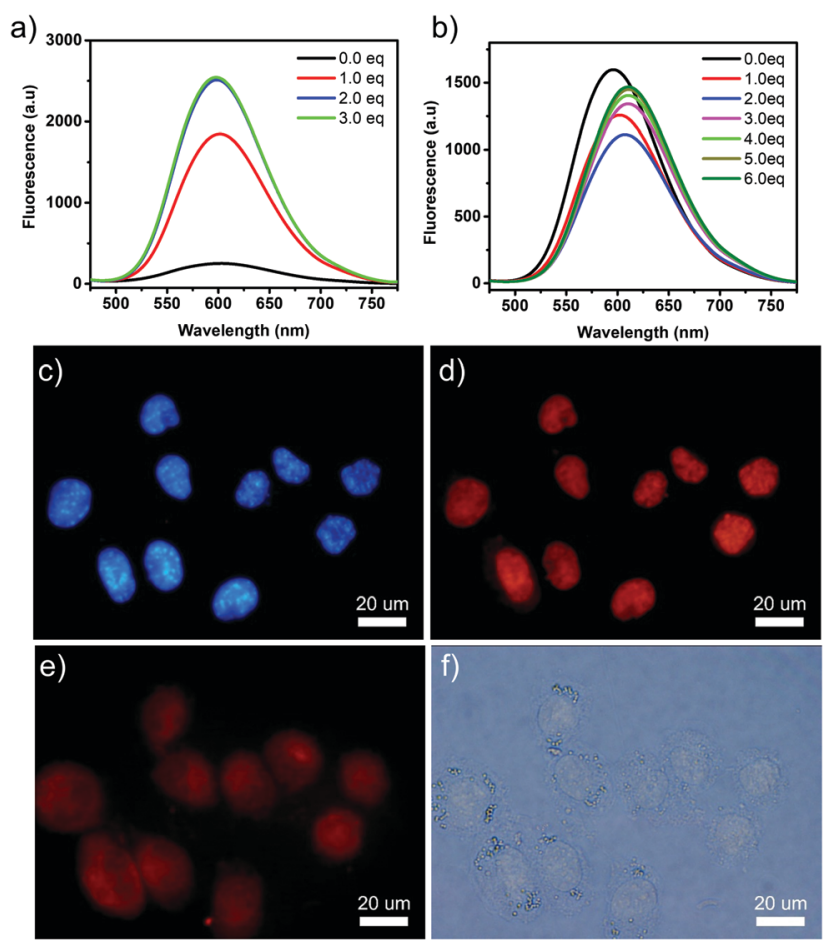

Fig. 4 Fluorescence spectral changes of (a) $1(3 \mu \mathrm{M})$ and (b) 1_CB[8] upon gradual addition of $\lambda D N A$ in water; epifluorescence microscopy pictures of HeLa cells treated with Hoechst $(5 \mu \mathrm{M})$ and with $1(1 \mu \mathrm{M})$ : (c) fluorescence of Hoechst, (d) fluorescence of $\mathbf{1}$, (e) the merged picture, (f) bright-field image.
1 as an excellent nuclear dye. 1_CB[8] complex was also used as a dye for staining the HeLa cells. The same experiment was performed. However, no evident fluorescence in the nucleus was observed. The 2D nanostructures were observed around the cells. This was because the size of the complex was not suitable for penetrating into the nucleus (Fig. S15, ESI $\dagger$ ).

\section{Conclusions}

In this work, we synthesized a host-guest supramolecular 2D nanostructure, which showed an evident AIE effect. The selfassembling process was evidenced by ${ }^{1} \mathrm{H}$-NMR spectroscopy and DLS experiments. A linear supramolecular formed first, followed by the final 2D self-assembled structure. TEM, SEM, AFM and SAXS studies showed the layer-by-layer 2D structure with a monolayer thickness of $1.8 \AA$. The high affinity for DNA and evident fluorescence enhancement made the guest molecule a novel and good candidate for use as a fluorescent DNA labelling reagent. Indeed, the guest molecule showed excellent performance as a biological fluorophore for the red staining of nuclear DNA with a good contrast. Interestingly, the fluorescence of this AIE dye could be turned on by the combination of the host-guest molecules. The functionalization of $\mathrm{CB}[8]$ might further provide site-specific cell dyes. Related research is still being carried out.

\section{Conflicts of interest}

There are no conflicts to declare.

\section{Acknowledgements}

The work was supported by the National Natural Science Foundation of China (21604046), the National Young Thousand Talents Program, Shandong Provincial Natural Science Foundation, China (ZR2016XJ004).

\section{Notes and references}

1 Y. Cheng, J. Dai, C. Sun, R. Liu, T. Zhai, X. Lou and F. Xia, Angew. Chem., Int. Ed., 2018, 57, 3123-3127.

2 G.-j. Liu, B. Wang, Y. Zhang, G.-w. Xing, X. Yang and S. Wang, Chem. Commun., 2018, 54, 10691-10694.

3 R. Chen, H. Jiang, H. Gu, Q. Zhou, J. Wu, D. Chen and J. Zhang, Chem. Commun., 2015, 51, 12220.

4 G. Yu, G. Tang and F. Huang, J. Mater. Chem. C, 2014, 2, 6609-6617.

5 X. Yao, X. Ma and H. Tian, J. Mater. Chem. C, 2014, 2, 5155-5160.

6 P. Wang, X. Yan and F. Huang, Chem. Commun., 2014, 50, 5017-5019.

7 N. Song, D. X. Chen, Y. C. Qiu, X. Y. Yang, B. Xu, W. Tian and Y. W. Yang, Chem. Commun., 2014, 50, 8231-8234.

8 D. Ding, K. Li, B. Liu and B. Z. Tang, Acc. Chem. Res., 2013, 46, 2441-2453. 
9 J. Liang, B. Z. Tang and B. Liu, Chem. Soc. Rev., 2015, 44, 2798-2811.

10 Z. Long, L. Mao, M. Liu, Q. Wan, Y. Wan, X. Zhang and Y. Wei, Polym. Chem., 2017, 8, 5644-5654.

11 A. Shao, Y. Xie, S. Zhu, Z. Guo, S. Zhu, J. Guo, P. Shi, T. D. James, H. Tian and W.-H. Zhu, Angew. Chem., Int. Ed., 2015, 54, 7275-7280.

12 J. Luo, Z. Xie, J. W. Y. Lam, L. Cheng, H. Chen, C. Qiu, H. S. Kwok, X. Zhan, Y. Liu, D. Zhu and B. Z. Tang, Chem. Commun., 2001, 1740-1741.

13 H. Tong, Y. Hong, Y. Dong, M. Häussler, Z. Li, J. W. Y. Lam, Y. Dong, H. H. Y. Sung, I. D. Williams and B. Z. Tang, J. Phys. Chem. B, 2007, 111, 11817-11823.

14 Q. Chen, N. Bian, C. Cao, X. L. Qiu, A. D. Qi and B. H. Han, Chem. Commun., 2010, 46, 4067-4069.

15 H. Shi, R. T. K. Kwok, J. Liu, B. Xing, B. Z. Tang and B. Liu, J. Am. Chem. Soc., 2012, 134, 17972-17981.

16 Y. Liu, C. Deng, L. Tang, A. Qin, R. Hu, J. Z. Sun and B. Z. Tang, J. Am. Chem. Soc., 2011, 133, 660-663.

17 X. Du, J. Qi, Z. Zhang, D. Ma and Z. Y. Wang, Chem. Mater., 2012, 24, 2178-2185.

18 Y. Hong, J. W. Y. Lam and B. Z. Tang, Chem. Commun., 2009, 4332-4353.

19 Y. Zhang, T.-G. Zhan, T.-Y. Zhou, Q.-Y. Qi, X.-N. Xu and X. Zhao, Chem. Commun., 2016, 52, 7588-7591.

20 S.-Q. Xu, X. Zhang, C.-B. Nie, Z.-F. Pang, X.-N. Xu and X. Zhao, Chem. Commun., 2015, 51, 16417-16420.

21 Y. Li, Y. Dong, X. Miao, Y. Ren, B. Zhang, P. Wang, Y. Yu, B. Li, L. Isaacs and L. Cao, Angew. Chem., Int. Ed., 2018, 57, 729-733.

22 H.-J. Lee, H.-J. Kim, E.-C. Lee, J. Kim and S. Y. Park, Chem. Asian J., 2018, 13, 390-394.
23 H. Liu, Z. Zhang, Y. Zhao, Y. Zhou, B. Xue, Y. Han, Y. Wang, X. Mu, S. Zang, X. Zhou and Z. Li, J. Mater. Chem. B, 2019, 7, 1435-1441.

24 K. Hyeong-Ju, W. D. Ryeol, G. Johannes and P. S. Young, Angew. Chem., Int. Ed., 2016, 55, 15915-15919.

25 X.-L. Ni, S. Chen, Y. Yang and Z. Tao, J. Am. Chem. Soc., 2016, 138, 6177-6183.

26 J. W. Colson and W. R. Dichtel, Nat. Chem., 2013, 5, 453-465. 27 S. Y. Ding and W. Wang, Chem. Soc. Rev., 2013, 42, 548-568.

28 H. Liu, X. N. Kan, C. Y. Wu, Q. Y. Pan, Z. B. Li and Y. J. Zhao, Chin. J. Polym. Sci., 2018, 36, 425-444.

29 C. L. Tan, X. H. Cao, X. J. Wu, Q. Y. He, J. Yang, X. Zhang, J. Z. Chen, W. Zhao, S. K. Han, G. H. Nam, M. Sindoro and H. Zhang, Chem. Rev., 2017, 117, 6225-6331.

30 X.-M. Chen, Y.-M. Zhang and Y. Liu, Supramol. Chem., 2016, 28, 817-824.

31 S.-Y. Jiang and X. Zhao, Chin. J. Polym. Sci., 2019, 37, 1-10. 32 M. Pfeffermann, R. Dong, R. Graf, W. Zajaczkowski, T. Gorelik, W. Pisula, A. Narita, K. Müllen and X. Feng, J. Am. Chem. Soc., 2015, 137, 14525-14532.

33 D.-H. Qu, Q.-C. Wang, Q.-W. Zhang, X. Ma and H. Tian, Chem. Rev., 2015, 115, 7543-7588.

34 J. Tian, L. Chen, D.-W. Zhang, Y. Liu and Z.-T. Li, Chem. Commun., 2016, 52, 6351-6362.

35 L. Yue, S. Wang, D. Zhou, H. Zhang, B. Li and L. Wu, Nat. Commun., 2016, 7, 10742.

36 L. Zhang, Y. Jia, H. Wang, D.-W. Zhang, Q. Zhang, Y. Liu and Z.-T. Li, Polym. Chem., 2016, 7, 1861-1865.

37 A. Clémence, S. Falk, L. Rémy, B. Guillaume, F. D. Céline, C. Fabrice, T. Patrick and T. F. Marie-Paule, ChemBioChem, 2007, 8, 424-433. 